\title{
Feed Formulation Based on Local Feed Resources and Its Effects on Nutritional-Related Blood Profile in Breeder Goats
}

\author{
Ghani AAA ${ }^{2}$, Shahudin MS ${ }^{2}$, Zamri-Saad $\mathrm{M}^{1}$, Zuki AB ${ }^{1}$, Wahid $\mathrm{H}^{1}$, Kasim A $^{4}$, Salisi MS ${ }^{1}$, \\ Hafandi $\mathrm{A}^{2}$, Hamzah $\mathrm{H}^{3}$, Daud $\mathrm{NHA}^{2}$, Hassim $\mathrm{HA}^{1,2}$ \\ ${ }^{1}$ Research Centre for Ruminant Disease, Faculty of Veterinary Medicine \\ ${ }^{2}$ Department of Veterinary Pre Clinical Sciences, Faculty of Veterinary Medicine \\ ${ }^{3}$ Department of Veterinary Pathology and Microbiology, Faculty of Veterinary Medicine \\ ${ }^{4}$ Department of Animal Science, Faculty of Agriculture, \\ Universiti Putra Malaysia, 43400 UPM Serdang, Selangor, Malaysia \\ haslizaabu@upm.edu.my
}

\begin{abstract}
A comparative study was conducted to determine the nutrient composition of different feed formulations and its effect on nutritional related blood profile in breeder goats. Eighteen female adult goats, Capra aegagrus hircus (Boer cross) were selected and allocated into three different groups $(\mathrm{n}=6)$ and assigned according to different feed formulations. Blood sampling was conducted before and after fourth weeks of feeding trial and analysed for selected parameters. Proximate analysis of diets was done and revealed comparable value of crude protein and crude fat. Glucose, total protein and calcium level in serum showed significant difference between groups (Pvalue $<0.05$ ) while cholesterol and fatty acid showed no significant difference (P-value $>0.05$ ). Fatty acid analysis of feed and serum showed polyunsaturated fatty acid was higher than satureated fatty acid. Overall, diet 3 shows the highest value of all blood parameters analysed in this study. Hence, it is very important to provide animal with nutrient according to production stages as sufficent protein and energy will improve the animal performance in terms breeding efficacy and quality of animal products. This study indicates that different feed formulation affects certain nutritional related blood profile in goat.
\end{abstract}

Key Words: Breeder Goats, Blood Profile, Proximate Analysis, Fatty Acid

\section{INTRODUCTION}

Establishment of commercial goat farms, especially smallholder farms, has become popular in recent years in Malaysia. Goats have been chosen because of their capability to produce meat and milk. Due to its high demand and good economic prospects, commercial goat farming has been gaining momentum in the recent years. Currently, the number of the goat farms in Malaysia has been increasing significantly. In 2010, a report from Ministry of Agriculture shown that the population of goats is about $34 \%$ of the total ruminant population in Malaysia. Goat population in Malaysia increased from 428,263 heads in year 2007 to 505,034 heads in year 2012 (DVS 2012). This trend was fuelled by the interest of the farmers towards fast turnover rate from goat production either from meat or milk.

Thus, to ensure sustainability of the goat industry in the future, a good husbandry program that includes vaccination practice, reproductive management and good feeding strategies should be designed and implemented in order to improve the herd health and farm performance (Mustafa 2010). With respect to nutritional management, adequate nutrient should be given to animals according to their sex, age, breed, production system (dairy or meat), body size, climate and physiological stages (Rashid 2008). But, to the majority of smallholders, balanced feeding is a minor concern due to time, cost and labor issues. Indeed, imbalanced feeding could affect the physiological function due to inadequate nutrient and further lead to reduction in performance. According to Komala et al. (2011), it is important to ensure the animals diet is formulated to support optimal 
production and be economical so that it does not burden the farmers. According to Waziri et al. (2010), blood examination could be used to monitor and evaluate health and nutritional status of animal. Analysis of biochemical properties such as glucose, total protein, blood urea nitrogen, creatinine and cholesterol is essential in diagnosing various nutritional, pathological and metabolic disorders (Daramola et al. 2005) in goats.

The objectives of this study were to determine the nutrient composition of feed material used in different feed formulations and to determine the effect of different formulations on nutritional-related blood profile such as glucose, total protein, calcium, cholesterol and fatty acids.

\section{MATERIAL AND METHODS}

\section{Experimental design}

Eighteen adult female Boer cross breed ranging from 8 to 9 months old and weighing about $28 \mathrm{~kg}$ were selected and kept under intensive farming system. They were then allocated into three different groups $(n=6)$ and assigned different feed formulations. The groups were labelled as Diet 1, Diet 2 and Diet 3. All goats were fed local feed resources such as Napier grass, local plants which include Macaranga sp., Mallotus sp., pressed soy waste and concentrate at different proportions. All goats are fed twice a day, in the morning and evening. The total feed given to the goats are $3.5 \mathrm{~kg} / \mathrm{animal} / \mathrm{day}$ as daily basis. Feed formulation for each group is as stated in Table 1.

Table 1. Feed formulation of Diet 1, Diet 2 and Diet 3

\begin{tabular}{lccc}
\hline \hline & Diet 1 $(\mathrm{g})$ & Diet 2 $(\mathrm{g})$ & Diet 3 $(\mathrm{g})$ \\
\hline Napier grass & 1500 & 1400 & 1370 \\
Mallotus sp. & 490 & 460 & 460 \\
Macaranga sp. & 490 & 460 & 460 \\
Pressed soy waste & 910 & 930 & 880 \\
Concentrate & 110 & 250 & 330 \\
\hline Total & 3500 & 3500 & 3500 \\
\hline
\end{tabular}

All goats were kept in the individual pens for monitoring throughout experimental period. The feeding trial lasted for 28 days where blood sampling was done twice; before the feeding trial and 28 days after feeding trial. Water were supplied ad libitum during the feeding trial and Stress Pack ${ }^{\circledR}$ was provided in drinking water every two week and after blood sampling procedures to reduce stress to the animals.

\section{Feed analysis}

The nutrient composition (ash; dry matter; crude protein; crude fibre; crude fat) for total mix ration of the feed given to the goats for each diet groups ( Diet 1; Diet 2; Diet 3) were determined by proximate analysis. Proximate analysis is the most common analysis performed on feed samples where it consists of a series of analyses to estimate the nutrient characteristic of feeds which includes the following: dry matter, crude protein, crude fat, crude fiber and ash. All the analysis were carried out according to certified procedures outlined by the Manual of Laboratory Techniques, Universiti Putra Malaysia which was developed according to procedures of AOAC (1990). The proximate analysis of the 
samples was done in 4 replicates. Besides proximate analysis, feed samples also were analyzed for fatty acid composition. Total fatty acid was extracted from feed samples by the method of Folch et al. (1957), modified by Rajion et al (1985), and described by Ebrahimi et al. (2012) and analyzed by gas liquid chromatography (Agilent 7890N) using a $30 \mathrm{~m} \times 0.25 \mathrm{~mm}$ ID $(0.20 \mu \mathrm{m}$ film thickness) Supelco SP-2330 capillary column (Supelco, Inc., Bellefonte, PA, USA).

\section{Blood sampling}

Blood samplings were carried out at day 0 and day 28 of feeding trial. The animals were properly restrained during blood collection. Blood samples were collected by venipuncture of the jugular vein. Prior to the venipuncture, the area for blood collection was swabbed with $70 \%$ alcohol. Then, approximately $10 \mathrm{ml}$ of blood was drawn out from each goat using a 21-gauge needle (Venoject@) into EDTA tube for hematological analysis and plain tube for serum biochemistry analysis.

\section{Blood analysis}

Blood samples from plain tube were centrifuged for 5 minutes at 5000 revolutions per minute (rpm) and separated serum was harvested and stored in plastic tubes and immediately sent to Clinical Pathology Laboratory, Faculty of Veterinary Medicine, Univrsiti Putra Malaysia for determination of total protein, cholesterol, calcium and glucose using Automatic Chemistry Analyzer (Model 902, Hitachi, JAPAN). One ml of serum was kept separately in $-20^{\circ} \mathrm{C}$ for fatty acid composition analysis. Total fatty acid was extracted from feed samples by the method of Folch et al. (1957), modified by Rajion et al. (1985), and described by Ebrahimi et al. (2012) and analyzed by gas liquid chromatography (Agilent $7890 \mathrm{~N})$ using a $30 \mathrm{~m} \times 0.25 \mathrm{~mm}$ ID $(0.20 \mu \mathrm{m}$ film thickness) Supelco SP-2330 capillary column (Supelco, Inc., Bellefonte, PA, USA).

\section{Statistical analysis}

All data were analyzed using Statistical Package for the Social Science (SPSS) version 22.0 for significant difference at $\mathrm{P}<0.05$. The mean of each parameter were tested using analysis of variance (ANOVA) and mean comparison using Tukey test.

\section{RESULTS AND DISCUSSION}

\section{Proximate analysis}

The results of proximate analysis for all feed formulation (Diet 1; Diet 2; Diet3) was tabulated in Table 2. Result obtained revealed that dry matter for Diet 3 was the highest followed by Diet 2 and Diet 1 . For the ash, Diet 2 showed the highest percentage and followed by Diet 3 and Diet 1. Crude fiber for all groups showed more or less a similar. Both crude protein and crude fat showed comparable value. For crude protein, Diet 3 showed the highest value followed by Diet 2 and Diet 1 . Similar to crude fat, Diet 3 contain the highest percentage of crude fat and followed by Diet 2 and Diet 1 . 
Table 2. Nutrient composition in different feed formulations

\begin{tabular}{lccc}
\hline \hline Nutrient composition $(\% \mathrm{DM})$ & Diet 1 & Diet 2 & Diet 3 \\
\hline Dry matter & 63.74 & 65.12 & 68.48 \\
Ash & 10.31 & 12.98 & 11.23 \\
Crude fiber & 20.44 & 20.44 & 20.35 \\
Crude protein & 8.32 & 15.08 & 20.01 \\
Crude fat & 2.10 & 2.27 & 2.36 \\
\hline
\end{tabular}

DM: dry matter

\section{Fatty acid composition of feed formulation}

Total fatty acid is a sum of total unsaturated fatty acid (monunsaturated and polyunsaturated fatty acid) and total saturated fatty acid. The total fatty acid content for all feed formulation are presented in Figure 1.

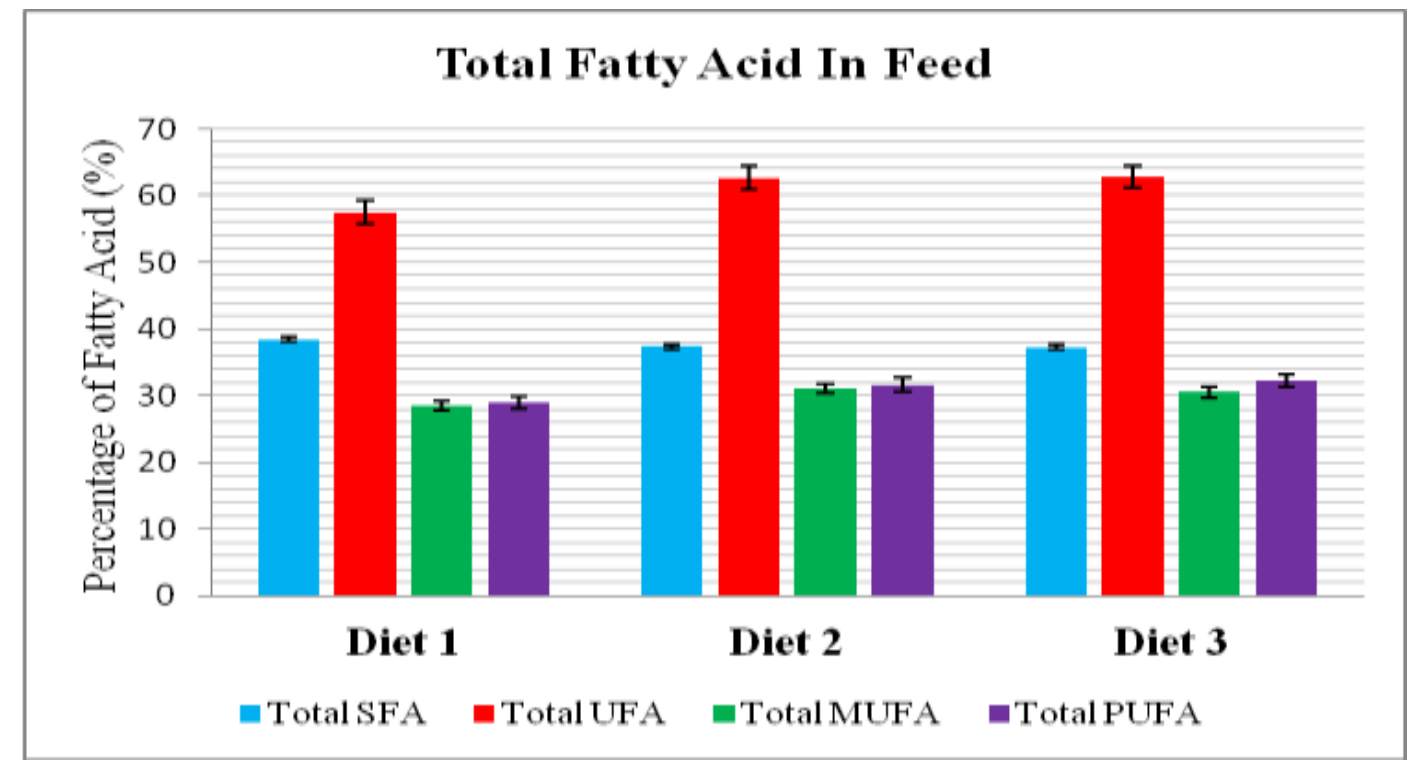

SFA: saturated fatty acid; UFA: unsaturated fatty acid; MUFA=monounsaturated fatty acid; PUFA: polyunsaturated fatty acid

Figure 1. Fatty acid composition in different feed formulations

From figure 1, all feed formulation shows high unsaturated fatty acid (UFA) compared to saturated fatty acid (SFA). The percentage of total UFA in Diet 1, Diet 2 and Diet 3 was $57.52 \pm 1.48,62.63 \pm 0.28$ and $62.78 \pm 0.27$, respectively. Diet 3 contain the highest total UFA followed by Diet 2 and Diet 1. This high UFA was contributed by high polyunsaturated fatty acid (PUFA) which mainly consist of C18:2, n-6 (linoleic acid) and C18:3, n-3 ( $\alpha$-Linolenic acid). The percentage of total PUFA in Diet 1, Diet 2 and Diet 3 was $29.00 \pm 0.78,31.62 \pm 0.16$ and $32.28 \pm 0.19$, respectively. Meanwhile, the percentage of total monounsaturated fatty acid (MUFA) in Diet 1, Diet 2 and Diet 3 was 28.52 \pm 1.14 , $31.01 \pm 0.15$ and $30.50 \pm 0.11$, respectively. For the total SFA, the percentage in Diet 1, Diet 2 and Diet 3 was $38.42 \pm 1.36,37.37 \pm 0.28$ and $37.22 \pm 0.28$, respectively. It shown that Diet 1 contain the highest total SFA followed by Diet 2 and Diet 3 in which more or less a similar value. 


\section{Nutritional-related blood profile}

In this study, a few blood parameters that are related to the nutritional status of the animals were determined such as total protein, glucose, calcium and cholesterol. The results of nutritional-related blood profile of goat fed with different feed formulation are presented in Table 3.

Table 3. Nutritional-related blood profile of goats in different feed formulation

\begin{tabular}{lrrr}
\hline \hline Blood parameter & \multicolumn{1}{c}{ Diet 1 } & \multicolumn{1}{c}{ Diet 2 } & \multicolumn{1}{c}{ Diet 3 } \\
\hline Total protein $(\mathrm{g} / \mathrm{l})$ & $63.56 \pm 3.79^{\mathrm{a}}$ & $69.83 \pm 3.14^{\mathrm{b}}$ & $72.82 \pm 1.29^{\mathrm{c}}$ \\
Glucose $(\mathrm{mmol} / \mathrm{l})$ & $2.27 \pm 0.37^{\mathrm{a}}$ & $3.05 \pm 0.22^{\mathrm{b}}$ & $3.97 \pm 0.17^{\mathrm{c}}$ \\
Calcium $(\mathrm{mmol} / \mathrm{l})$ & $2.21 \pm 0.03^{\mathrm{a}}$ & $2.56 \pm 0.08^{\mathrm{b}}$ & $2.95 \pm 0.04^{\mathrm{c}}$ \\
Cholesterole $(\mathrm{mmo} / \mathrm{l})$ & $3.13 \pm 0.07$ & $3.32 \pm 0.22$ & $3.76 \pm 0.32$ \\
\hline
\end{tabular}

Number followed by different superscript, in the same row significantly different at $\mathrm{P}<0.05$

After 28 days of feeding trial, blood results revealed that total protein, glucose and calcium give significant different among Diet 1, Diet 2 and Diet 3. Diet 3 contain the highest concentration of total protein followed by Diet 2 and Diet 1. Glucose concentration in Diet 3 contain the highest concentration followed by Diet 2 and Diet 1 . For the calcium, it was observed that Diet 3 contain the highest concentration of calcium followed by Diet 2 and Diet 1. Meanwhile, for the cholesterol concentration, there was no statistical difference observed between feed formulations.

\section{Fatty acid composition in serum}

Serum fatty acid composition is one of the indicators that directly related to the nutritional status of the animals from the feeding trial. The results of total fatty acid content in serum samples are presented in figure 2.

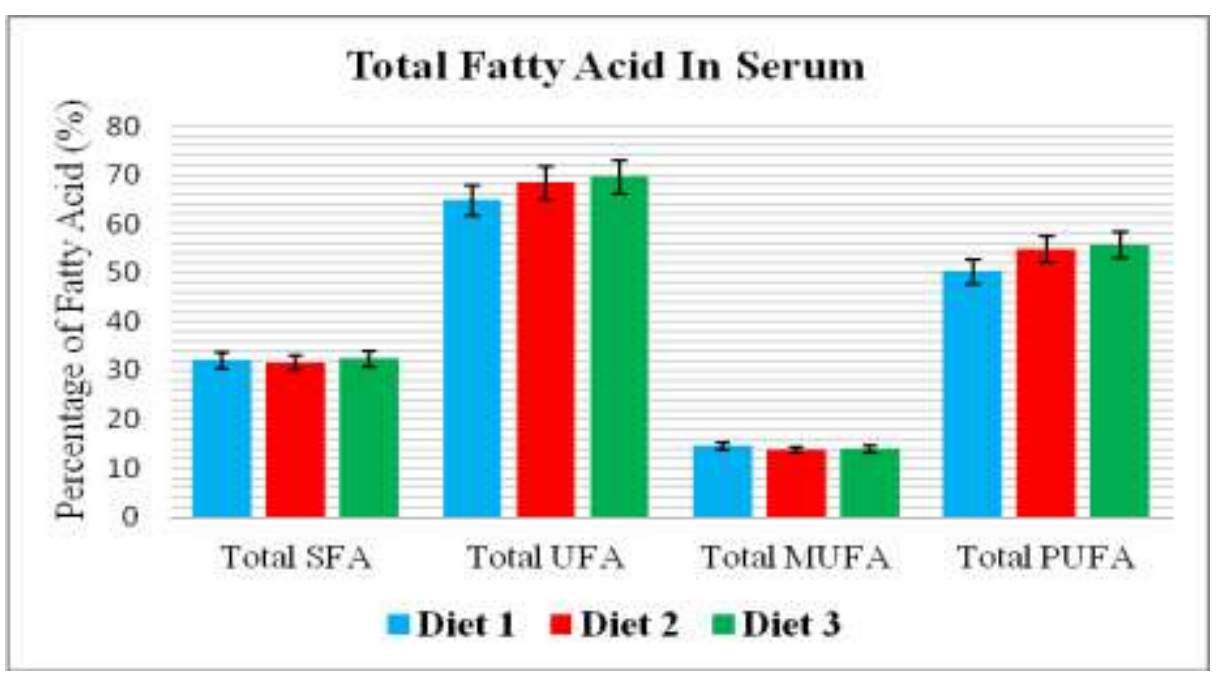

SFA: saturated fatty acid; UFA: unsaturated fatty acid; MUFA=monounsaturated fatty acid; PUFA: polyunsaturated fatty acid

Figure 2. Fatty acid composition of serum in animals fed different feed formulations 
After 28 days of feeding trial, fatty acid analysis in serum samples revealed that percentage of total fatty acid in all feed formulations were dominated by unsaturated fatty acid (UFA) where polyunsaturated fatty acid (PUFA) contributes larger portion than monounsaturated fatty acid (MUFA). The percentage of total UFA in Diet 1, Diet 2 and Diet 3 was $64.80 \pm 0.85,68.47 \pm 1.45$ and $69.64 \pm 0.91$, respectively. Diet 3 contain the highest total UFA followed by Diet 2 and Diet 1. The percentage of total PUFA in Diet 1, Diet 2 and Diet 3 was $50.21 \pm 0.33,54.77 \pm 2.08$ and 55.70 \pm 0.65 , respectively. Meanwhile, the percentage of MUFA in Diet 1, Diet 2 and Diet 3 was 14.59 $\pm 0.67,13.70 \pm 0.99$ and $13.94 \pm 0.91$, respectively. For the total saturated fatty acid (SFA), the percentage in Diet 1, Diet 2 and Diet 3 was $32.05 \pm 0.87,31.53 \pm 1.45$ and $32.44 \pm 0.81$, respectively. It is shown that Diet 3 contained the highest total SFA followed by Diet 1 and Diet 2, with significant differences.

\section{Discussion}

From the Table 2, it shown varies value of nutrient composition in different feed formulations. Dry matter content was highest in Diet 3 compared with Diet 1 and Diet 2. However, the percentage of dry matter in all feed formulation are lower than acceptable value as it is important to have the feed with high dry matter content, which mean low in moisture content. Moisture content would determine the successful storage of feed and high moisture content might favor toxin production and bacterial action (Ball et al. 2001). To increase dry matter content, drying process can be practice to eliminate moisture in the feed by allowing feed especially forages to expose with sunlight for a few hours before feed to the animals. Crude fiber revealed non-comparable value between diets which indicates that the fiber content might be similar. This is due to the proportion of feed ingredients almost similar especially Napier grass and local plants which are fibrous sources. As expected, as the amount of concentrate which is grain based feedstuff is increased in Diet 2 and Diet 3, the crude fat value for both feed formulation are affected and higher compared to Diet 1 as shown in Table 2. As the dietary protein given is increased in Diet 2 and Diet 3, it is clearly reflected by the crude protein value in both feed formulation. Crude protein in both feed formulation show high value and meet the requirement according to the physiological status of the animal.

From the figure 1, fatty acid analysis of feed sample revealed high polyunsaturated fatty acid (PUFA) especially in Diet 3 which rich in C18:2, n-6 (linoleic acid). Linoleic acid is very important and needs to be provided in diet as it one of essential fatty acid. Linoleic acid is able to improve pregnancy rate by enhancing progesterone secretion by granulosa cell. Soy bean including soy waste is one of the good sources for PUFA. Thus, pressed soy waste was chosen to be included as one of the ingredients for feed formulation in this study.

From the figure 2, nutritional-related blood profile result of all feed formulation, Diet 1 shows the lower value of total protein compared with Diet 2 and Diet 3. However, the values are still within normal range $(55-70 \mathrm{~g} / \mathrm{l})$. This might be due to low dietary protein intake. Commercial concentrate is formulated to contain high protein (14-16\%) and energy. In Diet 1, commercial concentrate proportion is lower than Diet 2 and Diet 3 thus affecting the total protein in serum. Determination of serum glucose level after feeding trial is very important to ensure that feed given to the animals supplies sufficient amount of glucose as glucose play important role as energy sources. Glucose level in Diet 2 and Diet 3 still within normal range (2.7-4.2 mmo//l) while glucose level in Diet 1 is low than normal range. This indicates that feed formulation in Diet 1 does not provide sufficient amount of glucose to the goats. Calcium is used as indicator as it is one of important 
minerals that need to be provided in diet sufficiently. All calcium value was within normal range (2.2-3.2 mmol/l) but Diet 3 shows the highest value compared to others. Calcium is very important as it serve various function such as skeletal formation, excitation of nerve impulse and cardiac muscle contraction. Calcium also is needed for good strength of skeleton so that animal will be fit for breeding and also to prevent from lameness. Cholesterol level in Diet 1 and Diet 2 still within normal range (2.1-3.4 mmol/l) while cholesterol level in Diet 3 is slightly higher than normal range. Keeping cholesterol within normal level are important to reduce the risk for cardiovascular disease.

From the figure 3, high values of unsaturated fatty acid (UFA) are dominated by polyunsaturated fatty acids (PUFA). PUFA is essential fatty acids that cannot be produced by the body and need to be provided in the diet. PUFA are good fatty acids that have many health benefits when used to replace saturated fatty acids. Omega-3 and Omega- 6 are classified as polyunsaturated fatty acids and play important roles in promoting a good health to animals. As all feed formulation used in this study contain pressed soy waste, it is a good source for PUFA.

\section{CONCLUSION}

Throughout 28 days of the experimental period, the implementation of different feed formulation does affect certain nutritional-related blood profile in goat such as total protein, glucose and calcium. Total protein, glucose, and calcium level in serum showed significant difference between groups while cholesterol and fatty acid showed no significant difference.

\section{REFERENCES}

AOAC. 1990. Official methods of analysis. 15th edition. Arlington (USA): Association of Official Analytical Chemists.

Ball D, Collins M, Lacefield G, Martin N, Mertens D, Olson K, Putnam D, Undersander D, Wolf M. 2001. Understanding forage quality. Park Ridge (USA): American Farm Bureau Federation Publication 1-01.

Daramola JO, Adeloye AA, Fatoba TA, Soladoye AO. 2005. Haematological and biochemical parameters of WAD goats. Livest Res Rural Dev. 17:8.

Ebrahimi M, Rajion MA, Goh YM, Sazili AQ. 2012. Impact of different inclusion levels of oil palm (Elaeis guineensis Jacq.) fronds on fatty acid profiles of goat muscles. J Anim Physiol Anim Nutr. 96:962-969.

Folch J, Lees M, Sloane-Stanely GH. 1957. A simple method for the isolation and purification of total lipides from animal tissues. J Biol Chem. 226:497-509.

Komala TS, Mahadi, Khairunnisak M, Ramlan M. 2011. Studies on Nutritionally-Related Blood Metabolites - Total Protein and Glucose Level in Goat of Kinta and Hilir Perak District. Malays J Vet Res. 2:9-16.

Mustafa HM. 2010. The prospects of Boer goats farming in Malaysia. Ministry of Agriculture and Agro-Based Industry, 400, 9-18.

Rahman MM, Rahman MR, Nakagawa T, Abdullah RB, Khadijah WEW, Akashi R. 2014. Effects of wet soya waste supplementation on the intake, growth and reproduction of goats fed Napier grass. Anim Feed Sci Technol. 199:104-112.

Rajion MA, McLean JG, Cahill RN. 1985. Essential fatty acids in the fetal and newborn lamb. Aust J Biol Sci. 38:33-40. 
Rashid M. 2008. Goats and their nutrition. Retrieved from https://www.gov.mb.ca/ agriculture/livestock/production/goat/pubs/goat-and-their-nutrition.pdf.

Waziri MA, Ribadu AY, Sivachelvan N. 2010. Changes in serum proteins, hematological and some serum biochemical profiles in the gestation period in Sahel goats. Vet Archiv. 80:215224.

\section{DISCUSSION}

\section{Question}

What is the important of this experiment?

\section{Answer}

This diet is for flushing program, beside that fat supplementation as energy supply during pregnancy can prevent ketosis 